\title{
RHENIUM AND TECHNETIUM (VI) AND MESO-(VII) SPECIES
}

\author{
S. K. MAJUMDAR, R. A. PACER and C. L. RULFS \\ Department of Chemistry, University of Michigan \\ Ann Arbor, Mich. 48104
}

(Received 17 May 1968)

\begin{abstract}
Spectrophotometric study shows that less than 35 per cent of normal perrhenate converts to a meso form in $15 \mathrm{M}$ base, and $K_{f} \sim 0 \cdot 1$. The species absorbs at $260 \mathrm{~m} \mu(\epsilon=6,400)$ and near $310 \mathrm{~m} \mu(\epsilon \sim 1,400)$, overlapping the normal perrhenate features. Reflectance spectra on an isolable barium salt, $\mathrm{Ba}_{3}\left(\mathrm{ReO}_{5}\right)_{2}$, confirm this resolution of the curve components. The variation of the barium salt solubility with concentration of aqueous hydroxide ion is consistent with the equilibrium deduced from spectrophotometry. Hydration is found for this salt and does not require the postulation of a dimeric form (to maintain 6-coordination); nor does this postulate seem to fit the equilibrium data or the i.r. absorption. No detectable amount of a comparable mesopertechnetate species is found in aqueous media of any alkalinity. However, pertechnetate fused in sodium hydroxide does give new absorption at 345,420 and $(\sim 570) \mathrm{m} \mu$ (of relative $\epsilon \mathrm{ca} .8 / 4 / 1$ ), which is probably due to meso (or, ortho) species. Attempts to isolate a (VI) salt, $\mathrm{BaTcO}_{4}$, from hydrazine-reduced (VII) in alkaline aqueous media, result in mixtures. Disproportionation of the intermediate state forms $\mathrm{TcO}_{2}$, and incidental $\mathrm{BaCO}_{3}$ gives "products" of high $\mathrm{Tc} / \mathrm{Ba}$ ratio. The red intermediate is more likely to be a Tc(V) species.
\end{abstract}

\section{INTRODUCTION}

THE LARGE differences in chemical behavior between manganese and technetium are of no greater interest than are the small differences between technetium and rhenium. Also, it is one of nature's "ingenious paradoxes" that the abundance of exclusively man-made technetium ( 6 per cent in fission products) may soon exceed that of its naturally-occurring but rare congener, rhenium.

The Noddacks [1] claimed several routes, e.g.,

$$
\begin{aligned}
& \mathrm{ReO}_{2}+2 \mathrm{NaOH} \rightarrow \begin{array}{r}
\mathrm{Na}_{2} \mathrm{ReO}_{3}+\mathrm{H}_{2} \mathrm{O} \\
\text { dk. brn. (IV) }
\end{array} \\
& \stackrel{\mathrm{O}_{2}}{\longrightarrow} \mathrm{NaReO}_{3} \rightarrow \mathrm{Na}_{2} \mathrm{ReO}_{4} \rightarrow \mathrm{Na}_{3} \mathrm{ReO}_{5}, \\
& \text { yell. (V) grn. (VI) yell. red (VII) }
\end{aligned}
$$

to the preparation of the rhenium(VI) and meso(VII) species in fused melts. Scharnow [2] isolated pale yellow $\mathrm{Ba}_{3}\left(\mathrm{ReO}_{5}\right)_{2}$ from strongly alkaline aqueous media, using various ratios of $\mathrm{Ba}(\mathrm{OH})_{2}$ and $\mathrm{Ba}\left(\mathrm{ReO}_{4}\right)_{2}$. Actually, $\mathrm{Ba} / \mathrm{Re}$ ratios of $3.4 / 2$ were found due to contamination with $\mathrm{BaCO}_{3}$. In contact with water the salt converts to normal perrhenate. More recently, Ward [3], Scholder [4] and

1. I. and W. Noddack, Z. anorg. Chem. 215, 129 (1933).

2. B. Scharnow, Z. anorg. Chem. 215, 183 (1933).

3. A. W. Sleight and R. Ward, J. Am. chem. Soc. 83, 1088 (1961); J. M. Longo, L. Katz and R. Ward, Inorg. Chem. 4, 235 (1965).

4. R. Scholder, Angew. Chem. 70, 583 (1958); R. Scholder and K. Huppert, Z. anorg. allg. Chem. 334, 209 (1965). 
Deschanvres [5] have published some structural work on mixed oxides and other rhenium species formed in alkaline fusions. Perovskite-structure meso-types have been reported, as well as low-temperature $\mathrm{M}_{3} \mathrm{ReO}_{5}$ types and higher-temperature $\mathrm{M}_{5} \mathrm{ReO}_{6}$ ortho-types. If it lacks an essential water of constitution, the maintenance of 6-coordination in the barium salt prepared the wet-way would imply a speculation like Peacock's [6] of $\mathrm{Re}_{2} \mathrm{O}_{10}{ }^{6-}$. Since 6-coordinate $\mathrm{Tc}$ (VII) would be even less stable (with respect to 4-coordination) than is $\operatorname{Re}$ (VII), he also proposes that it is unlikely that mesopertechnetates can be isolated from aqueous media, though they may be formed on oxide fusion.

While the oxide $\mathrm{ReO}_{3}$ is well known, its fusion in alkali results in disproportionation to $\operatorname{Re}(I V)$ and (VII). Simple (VI) compounds and some complexes are known, but good examples of bona-fide rhenates may not exist even though salts conforming to an $\mathrm{ReO}_{6}{ }^{-6}$ composition are known. In the case of technetium, even $\mathrm{TcO}_{3}$ is not well established. Gerlit [7] claimed evidence for a (VI) intermediate in the hydrazine reduction of alkaline pertechnetate. Rulfs, et al.[8] examined the growth of the intermediate spectrophotometrically in order to select an optimum time for precipitation of (?) $\mathrm{BaTcO}_{4}$. But small scale preparations of this material were too high in $\mathrm{Tc} / \mathrm{Ba}$ ratio, despite known contamination with $\mathrm{BaCO}_{3}$. It was decided that additional data on certain solubilities and information on the existence of aqueous meso-pertechnetate was desirable before repeating attempts to isolate this salt. These peripheral objectives have led to significant new information, but a (VI) salt of technetium has not been obtained.

\section{EXPERIMENTAL}

Reagents. Technetium-99, as ammonium pertechnetate solution, was obtained in good purity [8] from Oak Ridge National Laboratory. Pure sodium perrhenate was obtained from the Department of Chemistry, University of Tennesse. Other chemicals were of AR or CP grade, and Spectrochemical Grade solvents were used.

Barium salts of perrhenate or pertechnetate are easily crystallized from sat barium chloride solutions. A single recrystallization from distilled water gives salts of good purity.

Taking every reasonable precaution to previously remove carbonate and to exclude carbon dioxide, barium mesoperrhenate is readily separated by Scharnow's method, but at least 12-15 M $\mathrm{NaOH}$ should be used. In spite of precautions some $\mathrm{BaCO}_{3}$ will be present, and it is very difficult to obtain $\mathrm{Ba} / \mathrm{Re}$ ratios lower than $3 \cdot 5$ to $3 \cdot 7 / 2$.

Optical measurements. Ultra-violet and visible spectra were determined with a Beckman Model DU spectrophotometer using $1 \mathrm{~cm}$ silica cells. In one case, a pellet of sodium hydroxide was melted $\left(318^{\circ} \mathrm{C}\right.$ ) in a shallow depression (area, ca. $0.8 \times 1.2 \mathrm{~cm}$ ) on platinum foil and cooled to give a thin, slightly lensed, rectangular and weakly opalescent wafer. Most of the wafer could be broken out in one piece, wrapped in Saran wrap and mounted with Scotch tape in a cell carrier to position it in the optical path. A second pellet was melted only long enough to expel the ammonia from a tiny crystal of ammonium pertechnetate, giving an orange melt which cooled to a yellow solid. It was possible to examine the spectrum of the second wafer, blanked against the first, above $350 \mathrm{~m} \mu$ and throughout the visible region.

Infra-red spectra of barium meso-perrhenate in KBr-discs were recorded with a Perkin-Elmer Model 21 instrument. Powder reflectance spectra on this salt, alone and diluted with LiF, were

5. A. Deschanvres, Annali Chim. 4, 127 (1959).

6. R. D. Peacock, The Chemistry of Technetium and Rhenium, pp. 38-9. Elsevier, New York (1966).

7. J. B. Gerlit, Proc. Int. Conf. Peaceful Uses Atomic Energy, Geneva, Vol. 7, 145 (1955).

8. C. L. Rulfs, R. A. Pacer and R. F. Hirsch, J. inorg. nucl. Chem. 29, 681 (1967). 
generously run for us by Professor Robert Feltham of The University of Arizona. He employs a Zeiss PMQ-II instrument with a standard reflectance attachment [9].

The meaningful interpretation of u.v. spectra obtained in 10-15 $\mathrm{M} \mathrm{NaOH}$ solutions requires careful consideration of several factors. The molar absorptivity of hydroxide rises sharply below $240 \mathrm{~m} \mu$, but is only about $0 \cdot 1$ or less at higher wavelengths. Still, $10 \mathrm{M}$ base has a sizeable absorbance of 0.1 near $240 \mathrm{~m} \mu$ (Fig. 2 shows the absorbance of $12 \mathrm{M} \mathrm{NaOH}$ against water). On the one hand, this contribution (and much of the accompanying contribution of the refractive index term in Beer's Law) is adequately compensated by a reference solution of the same basicity. On the other hand, readings on such a system will be taken with significantly wider slit widths than are required with water alone. The effect of this is especially dramatic near the minima on those curve envelopes which result from "submerged" or partially overlapping peaks. If the concentration of carbonate is kept reasonably low, its contribution to absorbance above $240 \mathrm{~m} \mu$ is not important. More critical is the low solubility of sodium carbonate in concentrated hydroxide solutions; one must be wary of light scattering due to the development of a faint turbidity.

Analyses. The Ba, Tc(VI?) products, if freshly precipitated, were readily soluble in dilute hydrochloric acid. A suitable aliquot was neutralized with ammonia and evaporated on a planchet for technetium assay by calibrated comparative counting. The $\mathrm{pH}$ of another aliquot was adjusted with acetate buffer for the precipitation of barium chromate. This was centrifuged, washed, dissolved and measured colorimetrically. Only relative $\mathrm{Ba} / \mathrm{Tc}$ ratios were obtained, and these methods (valid within \pm 5 per cent) were not further refined in view of the obviously heterogeneous character of our product.

About $50 \mathrm{mg}$ of $\mathrm{Ba}_{3}\left(\mathrm{ReO}_{5}\right)_{2}$ (containing 0.7 mole of $\mathrm{BaCO}_{3}$ ) was dried with no loss of weight for $2 \mathrm{hr}$ at $115^{\circ} \mathrm{C}$. The essential, or high-temperature $\left(\mathrm{ca} .800^{\circ} \mathrm{C}\right)$, water was determined using a semimicro modification [10] of the Brush and Penfield method and weighings to $\pm 0.005 \mathrm{mg}$. While essential water does not characterize $\mathrm{BaCO}_{3}$ from most sources, Duval[11] shows a very small high temperature loss on a preparation from solution via ammonium carbonate. This could result from small amounts of bicarbonate or ammonium salt in his preparation, which should not exist in our material isolated from $15 \mathrm{M}$ caustic. The proportion of $\mathrm{BaCO}_{3}$ present in the sample is, of course, deducted from the sample weight in calculating the meso-salt hydration.

Solubilities. The solubility of scarce, radioactive or difficultly-prepared salts is conveniently examined using a scaled-down version of a Bronsted-Davies type of saturator column [12]. The entire apparatus is about $7 \mathrm{~cm}$ in height and the solids column is $1.0-1.5 \mathrm{~mm}$ i.d. barometer tubing. About $50-80 \mathrm{mg}$ of most finely-ground salts give adequate lengths of column packing. Three or four small drops of solvent are introduced on top of the thermostatted column, and 25-50 $\mu$ l. of the filtered saturate are withdrawn with an ultra-micropipet from the reservoir side for dilution and measurement by counting, spectrophotometry, etc. The performance of the column was tested by measuring the water solubilities of $\mathrm{K}_{2} \mathrm{CrO}_{4}, \mathrm{NaCl}$ and $\mathrm{AgCl}$. Data within $\pm 0 \cdot 8$ to $\pm 3 \cdot 1$ per cent of literature values are readily obtained.

While the solubility and equilibrium data might justify more elegant treatment, the effect of any $\mathrm{BaCo}_{3}$ present has been neglected as has the ionic strength effect on the solubility of our meso salt. The formation constant and related equilibria are dealt with only on a concentration basis. Specifically, for example, corresponding to $\left[\mathrm{OH}^{-}\right] \mathrm{M}$ of $15,10 \cdot 85$ and $5 \cdot 2,\left[\mathrm{H}_{2} \mathrm{O}\right] \mathrm{M}$ of $46 \cdot 6,50 \cdot 8$ and $54 \cdot 5$, respectively, are used. The use of such approximations for these media is more nearly a mandatory, than an arbitrary, choice. Strictly speaking, it must also be noted that while the solubility measurements were made at $20 \cdot 0 \pm 0 \cdot 1^{\circ} \mathrm{C}$, the spectrophotometric data were observed at $23 \pm 1{ }^{\circ} \mathrm{C}$.

\section{RESULTS}

Solubilities. The solubility of barium perrhenate was measured at $20 \cdot 0^{\circ} \mathrm{C}$ $(0.063 \mathrm{M})$ and at $35.0^{\circ} \mathrm{C}(0.148 \mathrm{M})$. The estimated heat of solution is +10.0

9. W. Silverthorn and R. D. Feltham, Inorg. Chem. 6, 1662 (1967).

10. A. G. Hybbinette and A. A. Benedetti-Pichler, Mikrochem. ver. Mik, Acta 30, 23 (1942).

11. C. Duval, Inorganic Thermogravimetric Analysis. Elsevier, New York (1953).

12. Rossotti and Rossotti, The Determination of Stability Constants, p. 190. McGraw-Hill, New York (1961). 
$\mathrm{kcal} / \mathrm{mole}$. These data are in good agreement with a reported value [13] of $8 \cdot 13$ $\mathrm{g} / 100 \mathrm{ml}$ at $30^{\circ} \mathrm{C}$.

Comparable measurements on $\mathrm{Ba}\left(\mathrm{TcO}_{4}\right)_{2}$ give $0.165 \mathrm{M}$ at $20^{\circ} \mathrm{C}$, and $0.361 \mathrm{M}$ at $35^{\circ}$. The heat of solution is estimated as $+9.2 \mathrm{kcal} / \mathrm{mole}$, which may be roughly compared with the range of 6.7 to 9.6 found [14] for $\mathrm{Cs}$, Tl(I) and Ag salts.

The solubility of barium mesoperrhenate was determined in various concentrations of aqueous sodium hydroxide at $20^{\circ} \mathrm{C}$. Normal perrhenate in the acidified saturates was measured spectrophotometrically. The results, shown in Table 1, are expressed in terms of molarity of the meso salt.

Table 1. Solubility of $\mathrm{Ba}_{3}\left(\mathrm{ReO}_{3}\right)_{2}$ in $\mathrm{NaOH}$

at $20^{\circ} \mathrm{C}$.

\begin{tabular}{ccl}
\hline $\begin{array}{c}\text { Aq. NaOH } \\
(\mathrm{M})\end{array}$ & $\begin{array}{c}\text { Solubility } \\
(\mathrm{M})\end{array}$ & Color of column \\
\hline 10.85 & 0.0148 & Yellow \\
5.20 & 0.104 & Yellow \\
2.60 & 0.245 & Lt. yell. \\
1.30 & 0.198 & White \\
0.65 & 0.128 & White \\
\hline
\end{tabular}

There is an obvious discontinuity reflecting the extensive reversion to normal perrhenate in dilute alkali. The solubilities at the two lowest concentrations of $\mathrm{NaOH}$ would extrapolate (linearly) to a value of $0.060 \mathrm{M}$ for sat. normal perrhenate in water at $20^{\circ}$ (cf. measured value is 0.063 ). Evidently, the true meso salt solubility may be less than $0.015 \mathrm{M}$ and appreciable normal perrhenate could exist in solution with $11 \mathrm{M}$ base.

Mesoperrhenate. The saturated $0 \cdot 10 \mathrm{M}$ solution of the barium mesosalt in $5 \cdot 2$ $\mathrm{M} \mathrm{NaOH}$ was examined in the visible region. No absorption equivalent to $\epsilon \geqslant 0 \cdot 1$ $/ \operatorname{Re}$ is found and the same is true in the $10.8 \mathrm{M}$ base (but, the $\operatorname{Re} M$ here is only 0.03 ). The salt does not impart any color to ethanol, DMF, acetonitrile or chloroform. Aqueous solutions $1 \mathrm{M}$ in perrhenate and $15 \mathrm{M}$ in $\mathrm{NaOH}$, with barium absent, show no visible absorption.

The u.v. spectra of $\mathbf{0 . 2 2 2} \mathrm{m} \mathrm{M}$ solutions of perrhenate in water were compared with the same concentration in $15 \mathrm{M} \mathrm{NaOH}$, but blanked against respectively appropriate solutions. There is no substantial absorption above $360 \mathrm{~m} \mu$, but a significant difference (constant after several hours) does exist on the high-wavelength side of the perrhenate curve. The apparent $\mathrm{ReO}_{4}{ }^{-}$absorption at $230 \mathrm{~m} \mu$ is reduced from 0.85 to 0.74 and additional new absorption is evident (see, Fig. 1, A). There is a major inflection in the new curve envelope and significant absorption in alkali extends to about $50 \mathrm{~m} \mu$ higher in wavelength.

Treating the new feature as being due to a single submerged curve of $\mathrm{ReO}_{5}{ }^{-3}$ partially overlapping the remaining $\mathrm{ReO}_{4}^{-}$(symmetrising its lo- $\lambda$ side based on the less distorted hi- $\lambda$ side, and reiterating once), gives a reasonable if not unique resolution of a new peak at $260 \mathrm{~m} \mu$. At or before this stage, closer inspection

13. W. T. Smith and G. E. Maxwell, J. Am. chem. Soc. 73, 658 (1951).

14. C. Keller and B. Kannellakopulos, Radiochim. Acta 1, 107 (1963). 


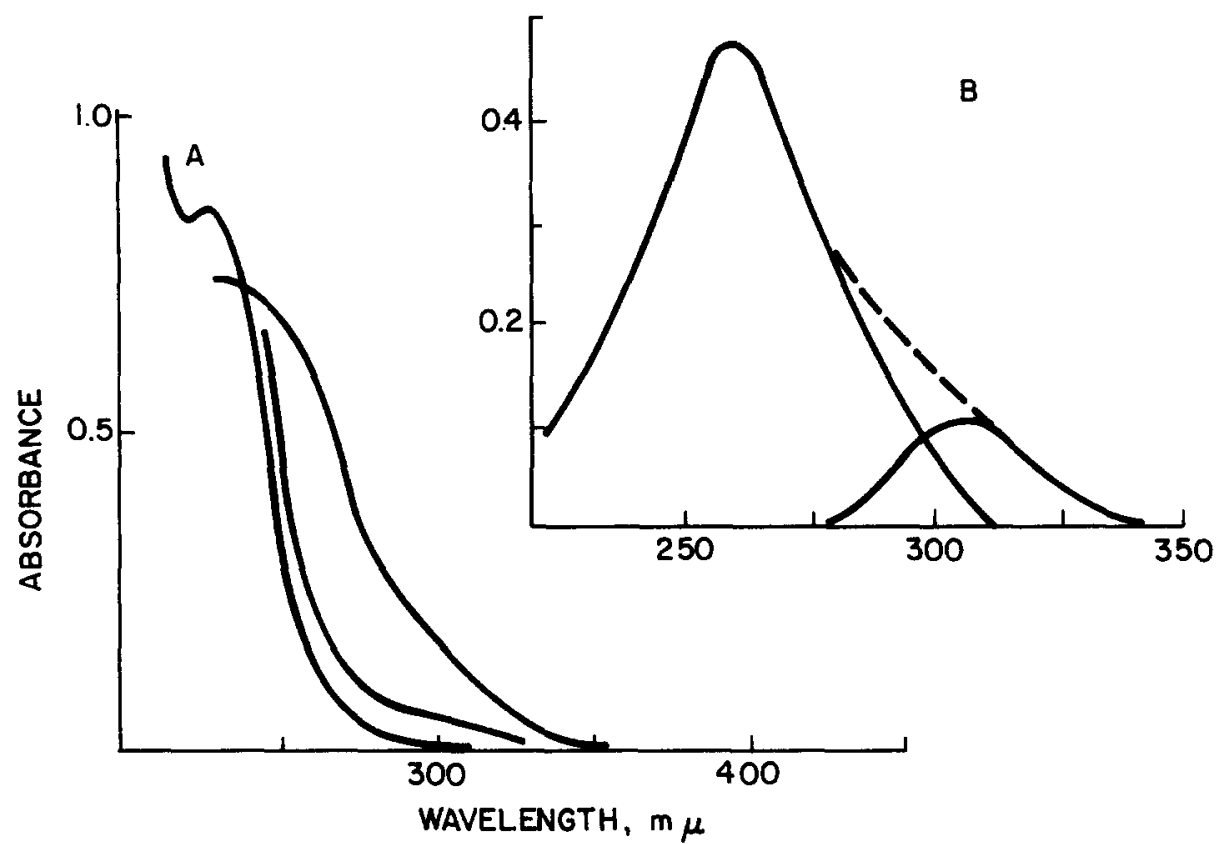

Fig. 1. Mesoperrhenate. A, $0.222 \mathrm{~m} \mathrm{M}$ normal perrhenate in water, to the right is the same concentration in $15 \mathrm{M} \mathrm{NaOH}$ vs. $\mathrm{NaOH}$, the intermediate curve is in $10 \mathrm{M} \mathrm{NaOH}$; $B$, resolution of the submerged and overlapped features ascribed to the existence of ca. 35 per cent of meso form in the $15 \mathrm{M} \mathrm{NaOH}$.

shows that another, smaller, hi- $\lambda$ component should be resolved from this envelope (See, Fig. 1, B).

Data from the strongly overlapped region of the normal and the 260-meso peaks ( 230 to $260 \mathrm{~m} \mu$ region) can be used to calculate the extent of normal to meso conversion,

$$
\mathrm{ReO}_{4}{ }^{-}+2 \mathrm{OH}^{-} \rightleftarrows \mathrm{ReO}_{5}{ }^{-3}+\mathrm{H}_{2} \mathrm{O}
$$

in $15 \mathrm{M} \mathrm{NaOH}$. The best fit is 66.2 per cent of normal in equilibrium with 33.8 per cent of the meso form, and the (concentration) formation constant (at $23^{\circ} \mathrm{C}$ ) is $0 \cdot 106$. The molar absorptivity for the meso peak at $260 \pm 4 \mathrm{~m} \mu$ is $6,400 \pm 500$, and at $308 \pm 10 \mathrm{~m} \mu$ is $1,400 \pm 300$. The spectrophotometric data for $10 \mathrm{M} \mathrm{NaOH}$ are consistent with the existence of the anticipated proportion of $c a .17$ per cent of the meso form.

While the results should be rounded to one or two significant figures, it is worth examining the extent to which the solubility data on $\mathrm{Ba}_{3}\left(\mathrm{ReO}_{5}\right)_{2}$ are compatible with this interpretation. The $K_{f}$ value of $0 \cdot 1$ implies less than 18 per cent meso in $10.85 \mathrm{M}$ base and less than 3 per cent in $5.2 \mathrm{M}$, and the isolation of the barium mesosalt $\left(\mathrm{K}_{\text {s.p. }}\right.$ est. $\left.10^{-9}\right)$ from solution depends on its low solubility. If the $2 \times 0.0148 \mathrm{M}$ total rhenium molarity in $10.85 \mathrm{M} \mathrm{NaOH}$ is equilibrated in solution as demanded by $\mathrm{K}_{f}=0 \cdot 106$, a $\mathrm{M}$ of $\mathrm{ReO}_{5}{ }^{-3}$ may be calculated. If, neglecting activity effects on the molar solubility of $\mathrm{Ba}_{3}\left(\mathrm{ReO}_{5}\right)_{2}$, one retains this saturation 
value as the $\left(\mathrm{ReO}_{5}{ }^{-3}\right)$ concentration for 5.2 and $2.6 \mathrm{M} \mathrm{NaOH}$ solutions, the $\mathrm{K}_{f}$ values which would fit the solubility data are $0 \cdot 07$ and $0 \cdot 10$.

If one assumed an alternative formulation such that,

$$
\mathrm{K}_{f}=\frac{\left[\mathrm{Re}_{2} \mathrm{O}_{10}^{6-}\right]\left[\mathrm{H}_{2} \mathrm{O}\right]^{2}}{\left[\mathrm{ReO}_{4}^{-}\right]^{2}\left[\mathrm{OH}^{-}\right]^{4}}
$$

a value of $1.65 \times 10^{-4}$ is calculated from the spectrophotometric data in $15 \mathrm{M}$ base. Then the $\mathrm{M}$ of $\mathrm{Re}_{2} \mathrm{O}_{10}{ }^{6-}$ in $10.85 \mathrm{M}$ hydroxide is only $\mathrm{ca} .8 \times 10^{-7}$. The calculated $\mathrm{K}_{f}$ 's in $5.2 \mathrm{M}$ and in $2.6 \mathrm{M}\left(\mathrm{OH}^{-}\right)$are $0.29 \times 10^{-4}$ and $2.10 \times 10^{-4}$, respectively. The internal consistency of the rounded figures in the two cases compare as 11,7 and 10 for the monomer vs. 17, 3 and 21 using the dimeric formulation. From this exercise one gains a preference for the simpler $\mathrm{ReO}_{5}{ }^{3-}$ formulation if not, in view of the approximations involved, a conviction.

A lack of essential water in the precipitated barium salt would constitute a reason [6] for postulating the dimeric form. One of our preparations lost no incidental water in $2 \mathrm{hr}$ of heating at $115^{\circ}$, but gave up water equivalent to $4.0 \pm$ $0 \cdot 1 \mathrm{H}_{2} \mathrm{O}$ per mole of salt at $800^{\circ} \mathrm{C}$. The i.r. spectrum of the mesosalt was also examined from 600 to $4,000 \mathrm{~cm}^{-1}$ in $\mathrm{KBr}$ discs. A considerable body of relatively recent work [15-20] is relevant to the interpretation of i.r. spectra of rhenium oxygen structures. The presence of bound water and of barium carbonate in this sample is important.

$A$ band at $687 \mathrm{~cm}^{-1}$ could be due to the carbonate and/or to combined water. In addition to a broad weak band for water bending at $1,625 \mathrm{~cm}^{-1}$, a very weak "combination" $(687 \pm 1,625)$ band occurs near $2,300 \mathrm{~cm}^{-1}$. Bands at 850 and at $1,415-1,490 \mathrm{~cm}^{-1}$ are due to carbonate. $A$ band at $1,057 \mathrm{~cm}^{-1}$ is at a rather high frequency for $\operatorname{Re}=0$, but is probably site-symmetry allowed for the aragonite form of $\mathrm{BaCO}_{3}$. Bands at 810 and $905 \mathrm{~cm}^{-1}$ are reasonable for (asym. and symm.) Re-0. Both the 2,450 and 3,400-3,460 $\mathrm{cm}^{-1}$ bands are assignable to water; a band at $1,750 \mathrm{~cm}^{-1}$ may be due to the same source. A similar band at 1,740-1820 has been found in moist $\mathrm{NaTcO}_{4}$, but was absent in $\mathrm{AgTcO}_{4}$ [17]. In any event, the 1,600 to $1,800 \mathrm{~cm}^{-1}$ region is free of bands for a known case of double $\mathrm{Re}-\mathrm{O}$ - $\mathrm{Re}$ bridging [17]. Moreover, we find no bands between 687 and $810 \mathrm{~cm}^{-1}$, while Ulbricht and Kriegsmann[17] assign $780 \mathrm{~cm}^{-1}$ as due to doubly-bridged $\mathrm{ReO}_{2} \mathrm{Re}$ in $\mathrm{Re}_{2} \mathrm{O}_{7}$.

While there is room for speculation concerning the manner in which the bound and/or hydrational water should be accommodated in the simpler meso species formulation, $\mathrm{ReO}_{5}{ }^{-3}$, there are three reasons why a formulation such as $\mathrm{Re}_{2} \mathrm{O}_{10}{ }^{-6}$ does not appear to be needed:

(1) The "hydration" permits 6-coordination without cross-linking.

15. R. F. Hirsch, Some Aspects of Chemistry of Technetium, Thesis, Univ. of Mich. (1965).

16. R. H. Busey and O. L. Keller, J. chem. Phys, 41, 215 (1964).

17. K. Ulbricht and H. Kriegsmann, Z. Chem. 7, 244 (1967).

18. S. B. Banerjee and B. Sur, J. inorg. nucl. Chem. 28, 2423 (1966).

19. D. K. Chakrabarti, V. I. Panesh and B. N. Ivanov-Emin., Zh. neorg. Khim. 12, 697 (1967).

20. K. Nakamoto, Infrared Spectra of Inorganic and Coordination Compounds. Wiley, New York (1963). 
(2) Equilibrium data for $\mathrm{Ba}_{3}\left(\mathrm{ReO}_{5}\right)_{2}$ solubility give a better fit with the monomeric form.

(3) Infra-red absorption of the barium salt is interpretable in terms of the monomer.

Professor Feltham's powder reflectance spectrum on isolated barium meso salt confirms the spectral features which are deduced by resolution from a two-fold excess of normal species in solution. On the solid salt a new peak near $405 \mathrm{~m} \mu$ and the persistence of considerable absorption to $c a .450 \mathrm{~m} \mu$ accounts for the yellow coloration, a weak peak at $590 \mathrm{~m} \mu$ is also present. More importantly, absorption peaks via reflectance are found at 274 and at $321 \mathrm{~m} \mu$. Such features normally appear $10-20 \mathrm{~m} \mu$ higher than corresponding absorptions in solution, hence these are in excellent agreement with our "resolved" features at 260 and $308 \mathrm{~m} \mu$.

Mesopertechnetate. For the less probable case of mesopertechnetate we have not been able to isolate, in the wet way, barium salts which seem to consist of other than barium carbonate with incidental contamination of normal pertechnetate. Neither is there any good spectrophotometric evidence for this form in aqueous media of any attainable alkalinity. But fusion in sodium hydroxide does give rise to spectral features which are reasonable for the meso-form.

With $0.13 \mathrm{M}$ pertechnetate in $12 \mathrm{M} \mathrm{NaOH}$ no absorption larger than 0.005 (i.e. $\epsilon \leqslant 0.04$ ) is found in $1 \mathrm{~cm}$ cells from $400 \mathrm{~m} \mu$ to $1,000 \mathrm{~m} \mu$. Using $\mathrm{NH}_{4} \mathrm{TcO}_{4}$ small and erratic absorbances are found at first, due to a gradual expulsion of microbubbles of $\mathrm{NH}_{3}$ gas. While no significant or new hi- $\lambda$ features are evident in the near ultraviolet for a $0.099 \mathrm{~m} \mathrm{M}$ solution in the $12 \mathrm{M} \mathrm{NaOH}$, abnormally high absorbances are found near the 246 and 288 features. This effect, however, seems to be only an instrumental artifact resulting from the necessity for wider slit widths when blanking and reading $12 \mathrm{M} \mathrm{NaOH}$ solutions (see, Fig. 2/A). The barely resolvable doublet at 244 and $248 \mathrm{~m} \mu$ normally shows apparent $\epsilon$ 's of 6200 for each peak. But the unresolved maximum near $247 \mathrm{~m} \mu$ in $12 \mathrm{M}$ $\mathrm{NaOH}$ has an apparent $\epsilon$ of nearly 6,500 . Even the $288 \mathrm{~m} \mu$ peak with a normal $\epsilon$ of 2350 is exalted to 2500 . For instrument balance when reading "base vs. base" as compared with "water vs. water" solutions, slit widths which are $0.2 \mathrm{~mm}$ larger are needed below $240 \mathrm{~mm}$ and decrease to less than $0.02 \mathrm{~mm}$ difference only above $330 \mathrm{~m} \mu$.

Paradoxically, since technetium does not occur with rhenium in nature and because rhenium is not present at significant concentrations in fission products, the chemical separation of these particular congener elements does not often arise as a practical problem. It is evident from the foregoing, however, that such a separation could be based on the differing tendency to form aqueous meso (VII) species, and the relative insolubility of the barium meso rhenium salt.

While evidence concerning aqueous species has been of principal concern, the effect of brief fusion in sodium hydroxide was examined. The cooled thin pellet does show appropriate higher wavelength peaks at $345 \pm 8,420 \pm 10$ and $570 \pm 20 \mathrm{~m} \mu$, whose apparent $\epsilon$ 's are in the approximate ratio of $8 \cdot 1 / 3 \cdot 9 / 1 \cdot 0$. The last peak, however, is likely to be due to some ortho form, $\mathrm{TcO}_{6}{ }^{-5}$, the proportion of which might increase on longer or higher-temperature fusion (See, Fig. 2(B)). 


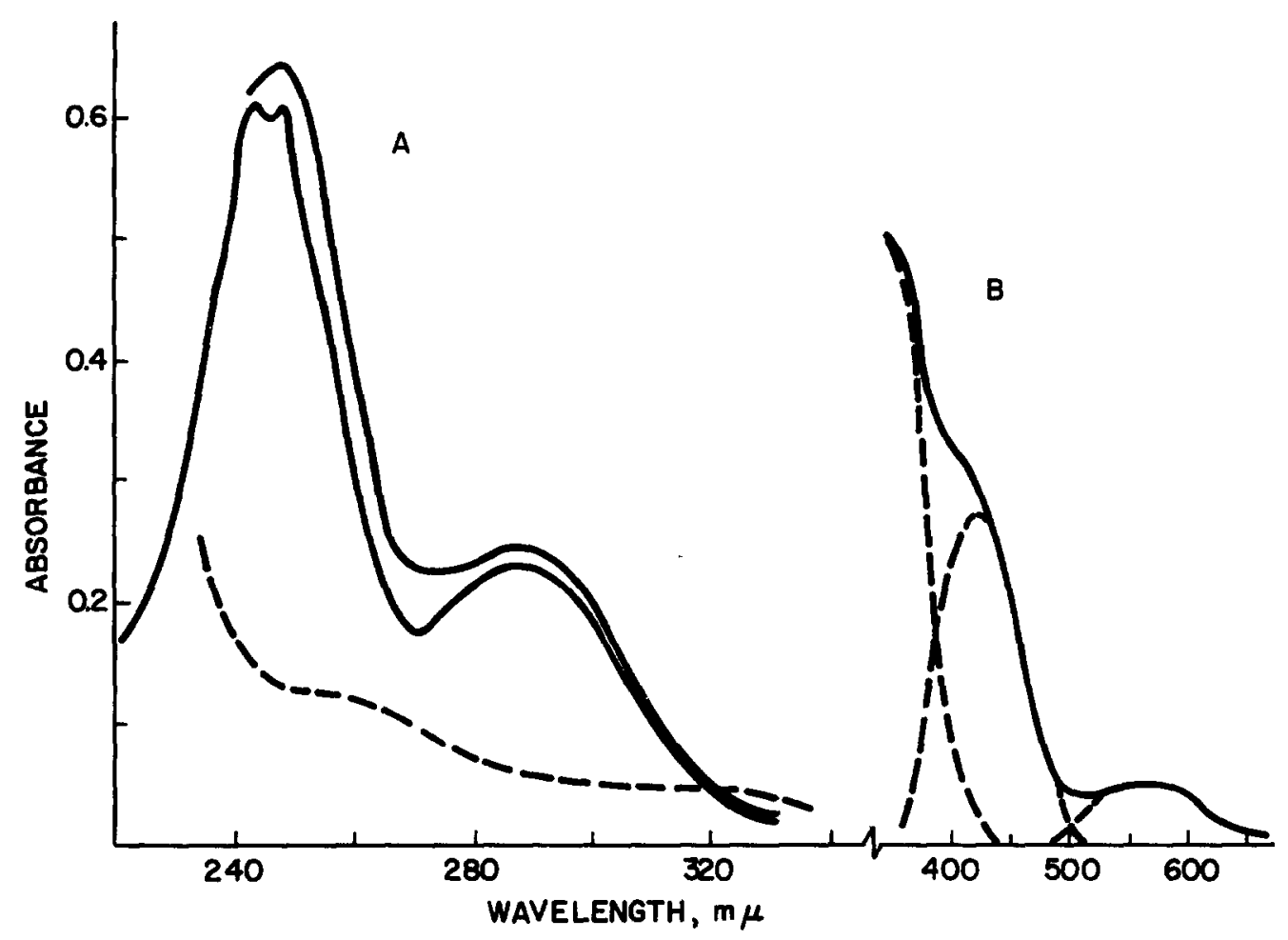

Fig. 2. Pertechnetate. A, the barely resolved doublet of ca. $0.1 \mathrm{~m} \mathrm{M}$ normal pertechnetate in water is unresolved (upper curve) at wider slit widths in $12 \mathrm{M} \mathrm{NaOH}$ vs. $12 \mathrm{M} \mathrm{NaOH}$. Dashed curve is absorbance of the base vs. water; $\mathrm{B}$, shows what are probably meso (and/or, ortho at $570 \mathrm{~m} \mu$ ) species features in a pellet of fused $\mathrm{NaOH}$.

Technetate (VI) state. The hydrazine reduction of pertechnetate in alkaline media was followed spectrophotometrically [8] showing the formation of a red intermediate (VI or V) state, prior to its disproportionation to (VII) and $\mathrm{TcO}_{2}$. An attempt to isolate $\mathrm{mg}$ of a barium salt of the intermediate gave a product of high $(>1 \cdot 1) \mathrm{Tc} / \mathrm{Ba}$ ratio, in spite of the known difficulty of avoiding $\mathrm{BaCO}_{3}$. This attempt has been repeated on a larger scale and with a fuller knowledge available of the solubilities of possible (VII) state barium compounds.

Using $0.3-0.01 \mathrm{M} \mathrm{TcO}{ }_{4}^{-}$media in 0.5 or in $3 \mathrm{M} \mathrm{NaOH}$ and saturated with $\mathrm{Ba}(\mathrm{OH})_{2}$, a range of conditions was tried. The amount of hydrazine used was varied from 0.2 to 5 times the molarity of the technetium, and products were removed after $<2,10$, or $30 \mathrm{~min}$ from the time of mixing. Reasonable care was taken to free reagents from $\mathrm{CO}_{2}$ and to exclude it during operations: high local excesses of reductant were avoided.

A pink to red coloration develops rather rapidly and, unfortunately, darkening and coprecipitation of some $\mathrm{TcO}_{2}$ initiates rather soon. The $\mathrm{Tc} / \mathrm{Ba}$ mole ratios of the product varied from 1.1 to 1.7 in these experiments, with 1.4 to 1.5 being common. The product appears to consist of a mixture of $\mathrm{BaCO}_{3}$, some $\mathrm{Ba}\left(\mathrm{TcO}_{4}\right)_{2}$ and considerable $\mathrm{TcO}_{2}$. No evidence could be found supporting the isolation of any $\mathrm{BaTcO}_{4}$.

Few (VI), but an increasing number of (V) state, compounds of technetium 
have been established or reasonably-postulated in recent years. The red ( $\epsilon$ $<1,000$ at $500 \mathrm{~m} \mu$ ) intermediate in the alkaline hydrazine reduction seems more likely to be a (V), than a (VI), state. There are a number of other cases of absorptions near 490-520 $\mathrm{m} \mu$ which may well characterize technetium (V), or (V)oxo, structures. Some apply to proven (V) states, others to postulated (V or VI) states. Technetium (V) oxo-oxinates [17] show a strong ligand band at $400 \mathrm{~m} \mu$ and a weaker $(\epsilon \sim 3,000)$ band near $520 \mathrm{~m} \mu$. Concentrated solutions of $\mathrm{HTcO}_{4}$ develop a band at $505 \mathrm{~m} \mu$ which has been ascribed to a reduction product [8]. The bisulfite reduction of pertechnnetate gives a $510 \mathrm{~m} \mu$ band, $\epsilon \sim 500$ [21]. Ascorbic acid reduction can give a (V) state[22] and the product absorbs at $490 \mathrm{~m} \mu, \epsilon=4,300[23]$. The (V) thiocyanate may not retain oxsgen ligands, but it also absorbs at $510 \mathrm{~m} \mu$ with $\epsilon=47,500$ in 60 per cent acetone [24]. The (V) level is an important intermediate in the polarographic reduction of neutral and alkaline pertechnetate solutions [25] and is probably an intermediate in the mechanism of the first irreversible reduction wave in acidic media even though three-, or four-, electron gross steps have been established for d.c. polarography and coulometry $[26,27]$.

Acknowledgement - This work has been supported by the U. S. Atomic Energy Commission, Contract AT(11-1)-1483.

21. R. A. Pacer, Analytical Chemistry of Technetium, Thesis, Univ. of Mich. (1965).

22. N. Golchert and J. Sedlet, Analytical Chemistry of Technetium, Paper, No. 153. A. C. S. Meeting, April 1967.

23. G. B. S. Salaria, C. L. Rulfs and P. J. Elving, Talanta 10, 1159 (1963).

24. C. E. Crouthamel, Analyt. Chem. 29, 1756 (1957).

25. L. Astheimer and K. Schwochau, J. electroanal. Chem. 8, 382 (1964); 14, 240 (1967).

26. G. B. S. Salaria, C. L. Rulfs and P. J. Elving, J. Chem. Soc. 2479 (1963).

27. C. L. Rulfs, R. Pacer and A. Anderson, J. electroanal. Chem. 15, 61 (1967). 